\title{
FORMAÇÃO PEDAGÓGICA DO PROFESSOR UNIVERSITÁRIO: UMA REFLEXÃO SOBRE A PROPOSTA DA UFG*
}

\author{
Dalva Eterna Gonçalves Rosa; \\ Sandramara Matias Chaves, \\ da Universidade Federal de Goiás.
}

\begin{abstract}
Resumo: Este artigo tem como referência o Programa de Formação para a Docência no Ensino Superior, instituído pela Universidade Federal de Goiás em 2006. Apresenta as ações propostas e discute as necessidades formativas e os saberes específicos para a docência nesse nível de ensino, com base na produção acadêmica sobre o tema e na produção dos professores participantes. Tem como objetivo a socialização das experiências vivenciadas na instituição. Nesta pesquisa foram sistematizados dados referentes ao perfil dos participantes, temáticas desenvolvidas nos estudos de casos apresentados no final dos cursos realizados pelos professores ingressantes. A discussão apontou para um quadro de diferentes ordens: política, estrutural, organizacional, epistemológica, didático-pedagógica. Dentre os vinte e oito eixos temáticos abordados, a maior incidência recaiu sobre a motivação de professores e de estudantes. Constatou-se que as necessidades formativas extrapolam o âmbito pedagógico, sugerindo uma relação entre o contexto universitário, a condição de trabalho docente e a prática em sala de aula. Isso indica demanda por maior investimento pessoal e institucional no desenvolvimento profissional dos docentes.
\end{abstract}

PALAVRAS-CHAVE: Docência no ensino superior. Programa de formação docente da UFG. Desenvolvimento profissional.

A preocupação da Universidade Federal de Goiás (UFG) com a formação pedagógica de seus professores não é recente. Desde a década de

\footnotetext{
* Artigo recebido em 31/5/2012 e aprovado em 24/8/2012.
} 
1990, esse tema é objeto de análise e de discussão em diferentes instâncias da instituição. Havia e ainda há demanda por debates a respeito do processo de ensino-aprendizagem por parte de determinados cursos de graduação, sobretudo no que se refere ao relacionamento com os alunos, à motivação dos estudantes para o estudo, ao desenvolvimento de um ensino significativo, à organização da prática docente e, ainda, a propostas de avaliação de aprendizagem mais coerentes. As solicitações são justificadas, via de regra, pela precária formação teórica e prática para o exercício do magistério, oferecida nos cursos de licenciatura, e pela ausência dessa formação nos cursos de bacharelado. Some-se a isso a pouca exigência da legislação educacional brasileira (Lei de Diretrizes e Bases da Educação Nacional - Lei n. 9394, de 20/12/1996 - LDB) quanto à formação profissional do professor no momento de seu ingresso na docência universitária.

A LDB estabelece o locus de formação do professor universitário no Título VI - Dos Profissionais da Educação, Art. 66: "A preparação para o exercício superior far-se-á em nível de pós-graduação prioritariamente em programas de mestrado e doutorado". Os cursos de pós-graduação stricto sensu, todavia, priorizam a pesquisa em detrimento do ensino, reafirmando a concepção embutida na organização dos cursos de bacharelado. Sendo assim, as licenciaturas e os cursos de pós-graduação precisam ser compreendidos no quadro da desvalorização do magistério como profissão e da epistemologia da educação como campo de conhecimento. As políticas públicas omitiram determinações quanto à exigência do preparo do professor de ensino superior no que diz respeito ao processo de ensinar, ficando a cargo da instituição educacional as iniciativas para capacitá-lo pedagogicamente.

Nesse contexto, o Fórum Nacional de Pró-Reitores de Graduação das Universidades Brasileiras (ForGrad) aprovou, em 1999, o Plano Nacional de Graduação que expressa preocupação com a formação de professores universitários e com a natureza da formação almejada: "[...] instituir, em todas as IES, programa de formação pedagógica em perspectiva continuada, provendo-se, inclusive, meios para adoção e absorção de novas tecnologias e metodologias de ensino". Recomenda ainda:"Os programas de pós-graduação devem oferecer a seus alunos a prática regular de monitoria supervisionada, disciplinas especiais e outras atividades correlatas, visando à preparação para a docência universitária nas respectivas áreas de conhecimento" (p. 30), buscando, assim, integrar graduação e pós-graduação na responsabilidade de formar professores.

Na mesma direção, a Associação Nacional dos Dirigentes das Instituições Federais de Educação Superior (Andifes) afirma que o processo 
de expansão das universidades federais, ocorrido nos últimos anos, estabelece modelos curriculares mais flexíveis e processos formativos que requerem maior protagonismo do estudante, ao lado de ações acadêmicas e institucionais que articulem a graduação e a pós-graduação, bem como reconhece que [...]"uma nova inserção do discente em seu processo formativo também exige programas para a formação continuada dos docentes da educação superior [...]" (Andifes, 2012, p. 13).

No campo da investigação, a docência universitária também recebeu maior atenção a partir da década de 1990. Benedito (1995) coloca a formação universitária em debate; Bireaud (1995) trata dos métodos pedagógicos no ensino superior; Masetto $(1982,1990,1996,1998)$ pesquisa a formação do professor de ensino superior, estudando a prática e os princípios teóricos da docência na universidade; Cunha (1992, 1994, 1996, 1997, 1998) investiga a formação continuada de professores universitários, a prática do bom professor, a inovação e a pesquisa na aula universitária e o desafio políticoepistemológico do ensino superior na sociedade contemporânea; Demo (1996) defende o ensino com pesquisa na prática do professor universitário; Marques (1992) discute a formação para a docência universitária; Morosini (1990, 1997, 1998, 2000) analisa a produção do ensino e da pesquisa na universidade, a docência universitária diante da realidade nacional e busca a melhoria do ensino e da formação de professores universitários via redes acadêmicas; Pimenta e Anastasiou (2002) discutem a construção da identidade docente no ensino superior; Anastasiou e Alves (2003) tratam dos processos de ensinagem na universidade; Rosa (2003) propõe a formação de formadores por meio da investigação-ação colaborativa; Cunha (2006, 2010) coloca em debate as trajetórias e os lugares de formação da docência universitária; Pimenta e Almeida $(2009,2011)$ analisam a organização e a implementação do programa de formação de professores da universidade de São Paulo, dentre outros.

Como pode se observar, novas perspectivas e velhos desafios se colocam para a profissão docente no contexto do século XXI. Nos últimos anos, ocorreram mudanças econômicas, sociais e culturais profundas e, com elas, o reconhecimento da importância da educação para o desenvolvimento do país, ampliando as demandas da sociedade para os sistemas educacionais que, por sua vez, as transferem para as instituições de ensino e para os professores. Essas mudanças, entretanto, nem sempre são orientadas por políticas públicas e/ou subsidiadas por recursos financeiros que possibilitem atender às expectativas. 
Pensar a profissão docente nessa conjuntura significa romper com a formação e com as práticas pedagógicas ancoradas em bases tradicionais como a transmissão de informações, a memorização de conteúdos, o trabalho individualizado - em busca de uma formação que prepare os professores para atuar com gerações que possuem estilos de aprendizagem e códigos de comunicação distintos; com a diversidade e a inclusão; com cenários interculturais em permanente mudança.

Desse modo, o desenvolvimento profissional dos formadores torna-se um desafio para as instituições de ensino superior. Este, compreende-se, é da responsabilidade de múltiplos atores, dentre eles o poder público, no sentido de recuperar o prestígio da carreira, as condições de trabalho e os salários; as universidades, por meio de uma nova cultura organizacional da formação continuada sistemática e intencional; e os próprios docentes, com disposição para se tornarem estudiosos do fenômeno educativo, comprometidos ética e politicamente com a apropriação de conhecimentos pelos estudantes.

Todavia, a competência profissional do professor de ensino superior ainda é compreendida, com base na tradição acadêmica, como o domínio do campo científico em que atua. Os aspectos pedagógicos e didáticos são pouco valorizados, visto que o processo de transmissão deve respeitar a sequência e a estrutura epistemológica dos conhecimentos, desconsiderando a natureza complexa e incerta do trabalho docente. Os escritos de Tardif (2002) esclarecem que boa parte do que os professores sabem - sobre o ensino, sobre os papéis a serem desempenhados e sobre como ensinar - provém de suas próprias histórias de vida, de forma especial, da vida escolar. E, quando começam a trabalhar, são principalmente essas crenças que eles reativam para solucionar seus problemas profissionais.

Na perspectiva de Ferry (1991, apud MARCELO GARCIA, 1999), a formação de professores diferencia-se de outras atividades de formação em três dimensões: a) trata-se de uma formação dupla na qual combinam a formação acadêmica com a formação pedagógica; b) é um tipo de formação que prepara profissionais que nem sempre se identificam com as características da docência; c) é uma formação de formadores, o que influencia a necessária correlação entre a qualificação de professores e a sua prática profissional.

De fato, trata-se de uma atividade multifacetada, pois há uma via de compreensão de mão dupla a ser percorrida pelos professores, que vai do conhecimento específico de cada campo do saber ao conhecimento pedagógico-didático, perpassando dimensões éticas e estéticas. Nem sempre a identidade docente é construída no espaço universitário. Neste, a pesquisa, 
pelos méritos dela advindos, tem se traduzido em reconhecimento dos pares na comunidade científica e o ensino, sobretudo na graduação, relegado a menor status acadêmico, fazendo com que pouca atenção seja dispensada à dimensão pedagógica do trabalho docente. Contudo, por ser uma formação de formadores não pode desconsiderar os professores como produtores de saberes sobre a docência.

Compreende-se, assim, a formação como uma dimensão pessoal de desenvolvimento humano que possui interface com outras dimensões: profissional, social, cultural, técnica, política. Uma de suas particularidades é que (a fim de que ela ocorra) "é preciso que se produzam mudanças através de uma intervenção na qual há participação consciente do formando e uma vontade clara do formando e do formador de alcançar objetivos explícitos" (MARCELO GARCIA, 1999, p. 21).

Com base nesse entendimento, fundamentada nos pressupostos da teoria crítica e de reconstrução social, e com o objetivo de melhorar o ensino de graduação, a Prograd (Pró-Reitoria de Graduação) estabeleceu, em 2006, a política de formação continuada do profissional docente da UFG, através do Programa de Formação para a Docência no Ensino Superior. Este é composto dos seguintes cursos e projeto: 1) curso: Docência no Ensino Superior/ Estágio Probatório (60h); 2) curso: Docência no Ensino Superior/Formação Permanente (48h); 3) curso: Docência no Ensino Superior/Professores Substitutos (32h); 4) curso: Formação em Gestão Acadêmica (48h), destinado a diretores, coordenadores, técnico-administrativos; e o projeto: Seminários de Formação na Graduação da UFG (8h), que contemplam discentes e docentes de todos os cursos e campi da instituição.

O programa visa propiciar espaço e lugar formativo que permitam aos professores ampliarem seus conhecimentos sobre a docência universitária. Objetiva consolidar uma concepção de formação profissional e docente mais ampla, por meio de discussões de fundamentos teóricos. Tem em vista a compreensão da Universidade Brasileira e da UFG, bem como do processo de ensino-aprendizagem, avaliação, relação professor-aluno, mediante situações-problema vivenciadas pelos professores no cotidiano de suas aulas. São também objeto de análise as diretrizes curriculares dos cursos e os seus projetos político-pedagógicos.

A proposição desse programa composto de várias e distintas ações formativas, em contraposição a ações pontuais e esporádicas, está ancorada na convicção de que, se a docência é uma profissão, faz-se necessário assegurar àqueles que a exercem um domínio adequado da ciência, da técnica e da arte, pois uma mudança educacional que conduza o ensino e 
a aprendizagem a patamares mais aceitáveis e mais justos socialmente é complexa e difícil, mesmo para os melhores professores.

No período de 2006 a 2011, participaram do programa 738 professores dos quatro campi; $50,81 \%$ pertencem ao sexo feminino e $49,19 \%$, ao masculino. Desses, 680 informaram sua maior titulação, sendo 58,97\% doutores, 39,26\% mestres, 1,18\% especialistas e 0,59\% graduados.

Observa-se que o número de professores que realizaram o curso Docência no Ensino Superior-Estágio Probatório representa 83,60\% do total. Se lembrarmos da obrigatoriedade desse curso para os professores iniciantes e compararmos esse percentual com 16,40\% dos cursos (para professor substituto, gestão acadêmica e formação permanente) que são oferecidos por demanda espontânea, teremos fortes indícios de que essa é uma experiência em construção, que ainda está por ser criada a cultura de formação contínua nas instituições de ensino superior, dentre elas a UFG. Os dados sugerem também a necessidade de um contingente significativo de profissionais envolvidos com a docência universitária, dada à sua especificidade, de modo que as demandas induzidas e espontâneas sejam prontamente atendidas, na perspectiva de se produzir mudanças no campo da atuação didática e nas políticas de qualificação do trabalho docente.

A importância atribuída à formação continuada dos docentes pela administração superior da universidade evidencia-se por meio da definição orçamentária e da infraestrutura (de modo a assegurar a estabilidade do programa), e da participação das seis pró-reitorias. Essas apresentam suas principais ações aos professores ingressantes e substitutos, com a finalidade de dar a conhecer a política global da instituição, situá-la no cenário nacional e internacional e promover a inserção dos docentes no contexto regional e local em que essa política materializa-se.

Os temas abordados nesses cursos são propostos por uma comissão de ensino (constituída pela Pró-Reitoria de Graduação - Prograd), composta de docentes de diferentes áreas de conhecimento, do coordenador do Programa de Formação para a Docência no Ensino Superior e de coordenadores de licenciatura, bacharelado e estágios. A comissão tem como referência as questões relativas ao ensino-aprendizagem mais emblemáticas e discutidas na Câmara de Graduação e em reuniões dos colegiados de cursos, bem como as avaliações realizadas pelos professores ao final de cada ação formativa.

No curso Formação em Gestão Acadêmica - destinado a diretores, coordenadores pedagógicos e técnico-administrativos -, os temas são relacionados ao plano de gestão estratégica, ao regulamento geral de cursos de graduação, às diretrizes curriculares, ao projeto político-pedagógico, 
à interação entre unidades acadêmicas, atividades administrativas, e aos programas de apoio institucional ao aluno de graduação.

O curso Docência no Ensino Superior/Formação Permanente, destinado aos professores experientes, aborda a formação pedagógica e a docência na universidade, relação ensino/pesquisa/extensão, concepção de ciência, currículo e ação docente, operações de pensamento e recursos metodológicos no processo de aprendizagem, tecnologias da comunicação e da informação na docência universitária, processos de avaliação da aprendizagem, ou outras temáticas propostas pelo grupo de professores, conforme seus interesses.

Quanto ao envolvimento, observa-se que os professores ingressantes apresentam certa resistência em participar do curso devido à obrigatoriedade, mas, ao final, afirmam que ele é bem organizado e alcança os objetivos previstos. Dizem que procuram participar da melhor maneira em todas as atividades propostas e admitem que esse é "bastante pertinente para a formação dos professores, causando uma mudança de postura" (Prof. Campus Catalão, 2010); "relevante para a formação dos professores" (Prof. Campus Jataí, 2010); "pertinente para o conhecimento da Universidade e para os professores com pouca experiência" (Prof. Campus Goiânia, 2010);"pertinente, pois permite a construção de um espaço de diálogo sobre as práticas" (Prof. Campus Goiás, 2011). Além desses depoimentos, consideram ainda que o curso é válido e necessário por possibilitar a socialização dos saberes de diferentes áreas, a troca de experiências entre os pares, a atualização de bibliografia, o acesso a conhecimentos pedagógicos e institucionais não contemplados na formação inicial. Já os participantes das demais ações formativas que compõem o programa não manifestam resistência por se tratar de demanda espontânea.

Os seminários de formação na graduação discutiram, no período de 2007 a 2008, os projetos político-pedagógicos e os estágios curriculares dos cursos de licenciatura e bacharelado, envolvendo 428 participantes, conforme demonstra o Gráfico 1.

A organização dos oito seminários realizados procurou seguir a lógica de áreas de conhecimento, sendo que algumas delas fizeram parte de mais de um evento, devido ao grande número de cursos e, por conseguinte, de seus representantes. Observa-se que a frequência oscilou entre $9 \%$ e $17 \%$ nas diferentes áreas de conhecimento, ou seja, grupos constituídos de 39 a 73 participantes. 


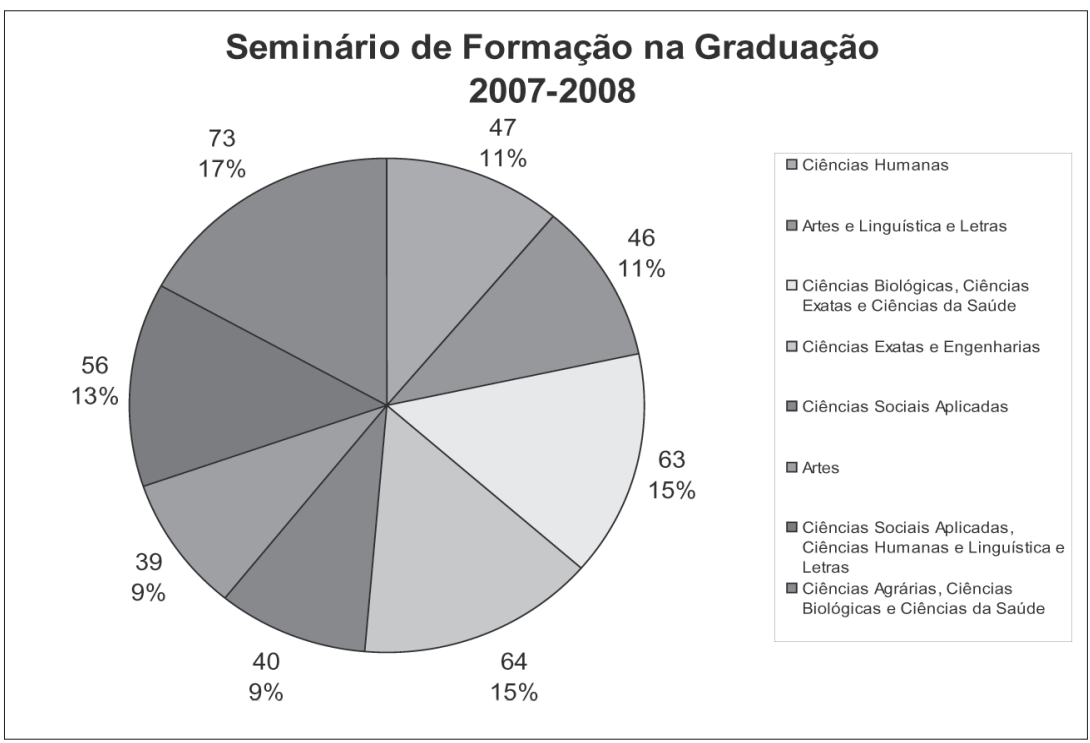

Gráfico 1 - Seminários de Formação na Graduação - 2007-2008.

Fonte: Prograd - UFG, 2008.

Contando com a participação de professores, representantes de estudantes, diretores, coordenadores pedagógicos e pessoal técnico-administrativo de todos os campi da universidade, os seminários não só subsidiaram a análise para reformulação curricular e a proposição de novos projetos de cursos, mas promoveram a integração do corpo discente, docente e técnico. A sistematização dos dados referentes a essa experiência evidenciou sua relevância e fez emergir outras temáticas, dentre elas a interdisciplinaridade e a práxis, discutidas no Seminário Geral de Graduação, em 2010, por 212 participantes que, também, socializaram suas experiências a respeito de metodologias inovadoras, como estudos de caso, problematização, projetos de intervenção no estágio curricular, aprendizagem baseada em problemas.

Esse movimento - envolvendo professores iniciantes e professores experientes - favoreceu a compreensão da necessidade de mudança nas concepções dos formadores de professores, bem como nos processos formativos que desenvolvem. Sem dúvida, evidenciou a falta de uma articulação institucional que favoreça uma formação que integre o conteúdo específico e o conhecimento pedagógico relativo a ele; que supere o individualismo em busca do trabalho coletivo, de modo que o professor sintase membro de uma equipe docente na qual possa apoiar-se para socializar os aspectos positivos do seu trabalho; bem como para discutir e encontrar 
alternativas para as dificuldades enfrentadas. Como se sabe, a passagem de uma abordagem conservadora para uma inovadora exige processos que abandonem as ações focalizadas no "escute, leia, decore e repita" para reproduzir (BEHRENS, 2005, p. 62).

Por compreender a importância de buscar ações que provoquem o professor e o aluno a questionar, refletir, construir, criar, projetar para produzir o conhecimento e promover momentos de troca com seus pares, o Programa Formação para a Docência no Ensino Superior propõe aos professores iniciantes que desenvolvam - em grupos formados, preferencialmente, por áreas de conhecimento distintas - estudos de casos que são apresentados e discutidos no final do curso. Vejam as temáticas abordadas pelos professores no Gráfico 2, a seguir.

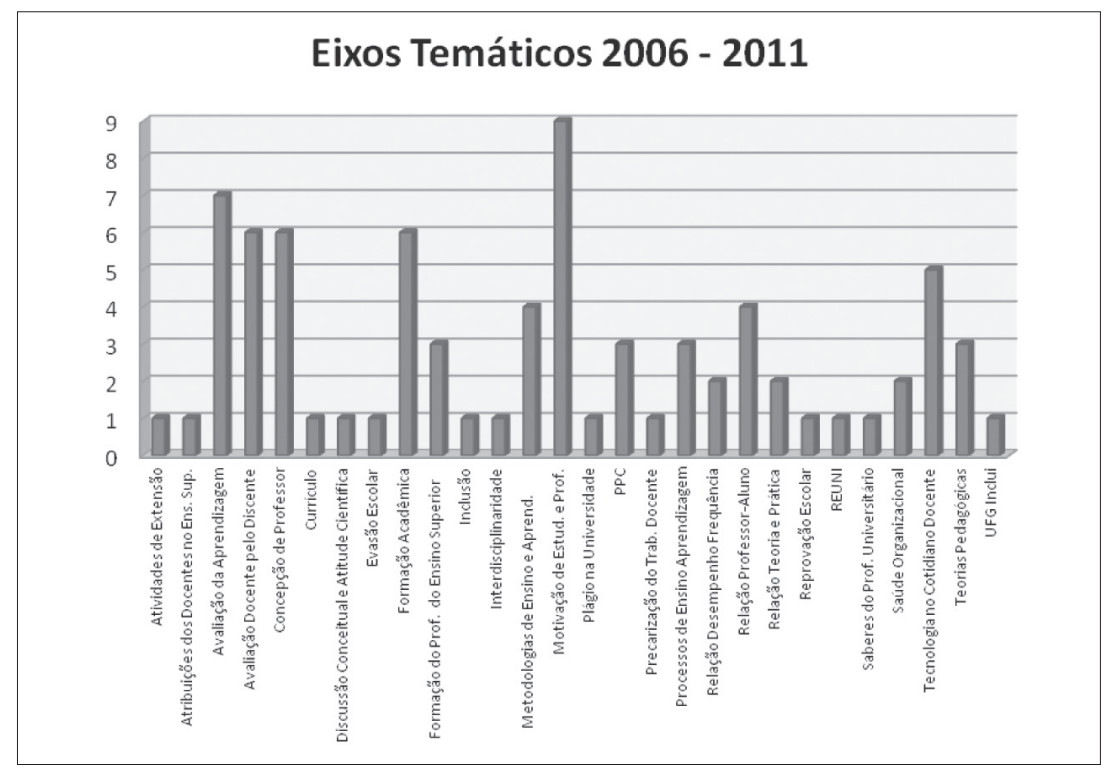

Gráfico 2 - Eixos temáticos 2006 -2011

Fonte: Prograd - UFG, 2011.

Conforme se lê no Gráfico 2, os estudos de caso, no interstício de 2006-2011, foram sistematizados em vinte e oito eixos temáticos, evidenciando as questões que mais estão atraindo a atenção dos professores iniciantes, quais sejam: motivação de estudantes e professores (9); avaliação da aprendizagem (7); formação acadêmica dos graduandos (6); concepção de professor (6); avaliação docente pelo discente (6); tecnologia no cotidiano 
docente (5); metodologias de ensino e aprendizagem (4); relação professoraluno (4). Neste artigo será tratado o eixo temático que reuniu maior número de trabalhos.

O eixo temático mais estudado foi a motivação de estudantes $e$ professores (9). Em um desses estudos, orientados por um formador, os professores iniciantes analisaram e discutiram a qualidade de vida e o trabalho do docente de ensino superior, tomando como sujeito os docentes da UFG. Consideram que a qualidade de vida não é indissociável do desempenho profissional, mas fundamental para a sua execução. Argumentam que a acelerada globalização técnica e científica impactou as formas de realização do trabalho e impôs condicionantes culturais à vida do professor que - cada vez mais cobrado por publicação e pesquisa, assoberbado de atividades acadêmicas, administrativas e de tarefas burocráticas - vive geralmente cansado, estafado, esgotado física, intelectual e emocionalmente. Ressaltam que do professor é também exigido ensino de boa qualidade; contudo, esse profissional encontra-se inserido em um sistema massificado, baseado na competitividade e produtividade, muitas vezes com recursos precários, com baixos salários e, como já dito, com aumento exacerbado de suas funções (SOUZA, et al, 2011).

Assim manifestaram os autores, mediante os dados deste estudo de caso:

Ao serem interrogados acerca do aproveitamento da vida, lazer e atividades correlatas, mais de $80 \%$ dos professores oscilaram entre as respostas 'muito pouco,',nada' e'mais ou menos', sendo que a maior parte aponta para'muito pouco'. [...] A recorrência de pensamentos negativos nos participantes desta pesquisa corresponde a aproximadamente $75 \%$ como sendo "frequentes" ou "algumas vezes". [...] Aproximadamente $50 \%$ dos entrevistados apresentam "insatisfação", "pouca satisfação" ou "satisfação mediana"' com o sono, a capacidade física para o trabalho, o nível de satisfação pessoal, as relações pessoais e com a vida sexual. Cerca de $30 \%$ dos entrevistados, ao responderem sobre a capacidade de concentração, se julgaram com problemas neste aspecto. (SOUZA et al, 2011, p. 22)

Concluem que todos esses fatores geram mal-estar entre os docentes, cujas consequências já foram constatadas e divulgadas por outras pesquisas: "desmotivação pessoal, elevado índice de absenteísmo, de abandono, insatisfação profissional traduzida numa atitude de desinvestimento e de indisposição constante" (NÓVOA, 1992, p. 20). A expectativa do grupo com o desenvolvimento desse trabalho "é promover uma reflexão sobre o que 
estamos fazendo para melhorar e transformar tal cenário positivamente" (SOUZA, et. al, 2011, p. 23).

Para tentar evitar, segundo ESTEVE (1999), o mal-estar docente, o sofrimento vivido pelo professor por causa das condições de trabalho que enfrenta e pelas demandas que se impõem ao exercício profissional, outro grupo de professores do curso afirma, em seu estudo, serem necessárias reflexões e, principalmente, proposição de práticas docentes que levem à ruptura do isolamento e à construção de uma espécie de resiliência individual e coletiva, que possa proteger os profissionais e garantir a qualidade do trabalho. Consideram que a explicação mais convincente para a motivação do professor no exercício de sua profissão "só pode ser a satisfação, o sentido e o significado que o trabalho tem para ele" (OLIVEIRA JÚNIOR et al., 2007, p. 6). Propõem que o exercício da interdisciplinaridade no contexto acadêmico possa ser uma das estratégias para lidar com a complexidade desse contexto problemático.

Segundo Gusdorf (1977, p. 637), “A significação fundamental da interdisciplinaridade é a de uma chamada à ordem do humano, de um humanismo da pluralidade e da convergência"; já Sommerman (2006, p. 63) considera a interdisciplinaridade "um verdadeiro diálogo" que requer o favorecimento das trocas intersubjetivas dos diferentes especialistas, nas quais cada um reconheça, em si mesmo e nos outros, não só os saberes teóricos, mas os saberes práticos e existenciais. Apoiados nesses teóricos, os professores sugerem algumas ações que podem ser colocadas em prática para fomentar o exercício da interdisciplinaridade nas equipes docentes dos cursos em que atuam. Essa interdisciplinaridade apresenta os seguintes esboços:

Maior integração dos conteúdos das disciplinas com um esforço dos docentes e discentes para explicitação e reflexão de tais relações ao longo do seu desenvolvimento. [...] disposição de compartilhar objetivos, decisões, responsabilidades e também resultados. [...] disposição de ouvir e considerar as experiências e os saberes de cada membro do grupo, pois o trabalho em equipe não implica em eliminar as diferenças (sociais, culturais etc.) entre os membros e, sim, trabalhar essas diferenças. (OLIVEIRA JÚNIOR et al, 2007, p. 7-8)

Nesse contexto, um terceiro grupo de docentes questiona: Como motivar o aluno, estando o próprio professor desmotivado? Como mobilizar o interesse do aluno para as atividades em sala de aula? Essa equipe argumenta que o excesso de trabalho ou a falta de conhecimento de aspectos que permeiam o trabalho pedagógico fazem com que os professores deixem de explorar a força motivacional de seus alunos para a execução das 
atividades diárias. Assevera que muitos docentes atribuem o fracasso em suas disciplinas à falta de motivação intrínseca dos alunos e que, consciente ou inconscientemente, negligenciam seus papéis como mobilizadores da motivação extrínseca no processo de aprendizagem (SILVA et al, 2011).

Sobre essa situação, Costa et al. (2010) alertam que, no momento de se inferir se há ou não motivação por parte dos acadêmicos, é necessário lembrar que existe uma forte interação entre as características do acadêmico e os fatores do contexto, a tarefa a ser executada, o período cursado e o professor. Amparados por Tapia e Fita (2006) ressaltam, ainda, que os alunos não estão motivados ou desmotivados abstratamente. A motivação surge, ou não, em função do significado do trabalho que se pretende realizar e cabe ao professor criar contextos significativos que afetem a motivação e a aprendizagem.

Nessa linha de raciocínio, Silva et al. (2011, p. 4) advertem:

o estilo motivacional do professor é considerado uma característica vinculada à personalidade, mas é vulnerável a fatores sociocontextuais, como, por exemplo, o número de alunos em sala de aula, o tempo de experiência no magistério, a idade, as interações com a direção da escola, as concepções ideológicas, entre outros.

No estudo de caso em epígrafe, propôs-se investigar a influência dos professores - de um dos campi da UFG, com tempo de docência inferior e superior a cinco anos - na motivação dos alunos para o processo ensinoaprendizagem. Fizeram parte do estudo vinte professores efetivos, com titulação de doutor, divididos em dois grupos: um composto de professores com tempo inferior a cinco anos e outro de professores com mais de cinco anos de docência no ensino superior. Aplicaram-se questionários aos alunos matriculados em uma das disciplinas de cada professor participante do estudo, sendo escolhidos, aleatoriamente, cinco deles para responder à enquete. Essa metodologia resultou na aplicação de 100 questionários.

Os autores afirmam, apoiados em Bzuneck (2001), que os efeitos imediatos da motivação dos alunos consistem no seu envolvimento ativo nas tarefas pertinentes ao processo de aprendizagem, o que implica terem escolhido a realização dessa tarefa entre muitas outras atividades ao seu alcance. Mas isso não necessariamente assegura que o comportamento iniciado será mantido pelo esforço e pela perseverança, se dificuldades ocorrerem, o que significa que, para motivar o aluno a ir para a aula e dela participar, é necessário que os membros da instituição, em especial os 
professores, sejam criativos, permitindo o desenvolvimento do potencial criador dos alunos (YELÓS, 2002, apud SILVA et al., 2011, p.10).

Nessa pesquisa verificaram-se os seguintes dados,

A despeito de a maioria dos alunos ( $82 \%$ dos alunos de professores com tempo de docência superior a cinco anos e $96 \%$ dos alunos de professores com tempo de docência inferior a cinco anos) sentir vontade de ir para a aula, $10 \%$ dos alunos de professores com tempo superior a cinco anos de docência têm a sensação de que não aprenderam nada e somente $4 \%$ relatam que aprenderam bastante do que foi ensinado e sentem-se motivados a pesquisar mais sobre o assunto. Enquanto, nenhum (0\%) dos alunos de professores com tempo inferior a cinco anos de docência tem a sensação de que não aprendeu nada, $20 \%$ relatam que aprenderam bastante do que foi ensinado e sentem-se motivados a pesquisar mais sobre o assunto. (SILVA et al., 2011, p.13)

Assim, pode-se inferir que a experiência contribui para o desempenho criativo em atividades que exijam conhecimento especializado, como verificado no grupo com mais tempo de docência, mas - mediante as afirmações dos alunos pesquisados - essa criatividade oriunda do conhecimento especializado não se refletiu no aprendizado. Seria a linguagem técnica um dificultador?

No que diz respeito à metodologia, $64 \%$ dos alunos de professores com tempo de docência superior a cinco anos afirmam que gostam tanto do método de ensino que nem veem a aula passar; enquanto $12 \%$ dos alunos de professores com tempo de docência inferior a cinco anos fazem essa mesma afirmação.

Os dados demonstram que os professores mais experientes agregam aos seus saberes especializados conhecimentos sobre o contexto cultural dos alunos, sobre a instituição em que trabalham, e esses já se encontram em uma fase de "estabilização" (HUBERMAN, 1992), o que influencia positivamente na construção de sua forma própria de agir, de sua teoria pessoal em relação à gestão da aula, atraindo a atenção dos alunos. Contudo, a ação docente não é a única responsável pela aprendizagem, pois esta envolve aspectos complexos, com múltiplos fatores que não podem se reduzir ao agir do professor.

Em relação à duração das aulas, $30 \%$ dos alunos de professores com tempo de docência superior a cinco anos acham que essas demoram o tempo suficiente para se entender o conteúdo, e $6 \%$ de seus alunos acham que a aula demora uma eternidade para acabar. Por outro lado, $74 \%$ dos alunos de professores com tempo de docência inferior a cinco anos acreditam que o 
tempo das aulas é suficiente para aprenderem o conteúdo proposto, e 14\% acham que leva uma eternidade para acabar a aula (SILVA et al, 2011).

Ao iniciarem em seu percurso profissional, que possibilita o confronto com o novo e a exploração de inúmeras possibilidades de ação (HUBERMAN, 1992), os professores com menor tempo de experiência procuram construir saberes no contexto da prática profissional, apreender a dinâmica de funcionamento da instituição, conhecer os modos de aprendizagem dos alunos e ajustar sua atuação ao cronograma de trabalho, talvez com mais preocupação de ministrar todo o conteúdo previsto.

Constatou-se, por meio de média ponderada das respostas, que os professores com tempo de docência superior a cinco anos foram classificados pelos alunos como pouco motivadores na disciplina em questão, com a pontuação 9,91 (em uma variação de 0 a 16). Em contrapartida, os professores com tempo de docência inferior a cinco anos foram classificados como motivadores, recebendo 11,80 de pontuação (SILVA et al, 2011).

O professor que está iniciando a carreira acadêmica quer conquistar o reconhecimento dos colegas e dos estudantes. Provavelmente, em consequência disso, ele se esforce mais no preparo das aulas e na motivação dos alunos. Além disso, a relação professor-aluno no processo de ensinoaprendizagem é mediada por muitos elementos, sendo um deles a linguagem, que pode vir a ser um fator facilitador ou complicador. Teriam os professores com menor tempo de experiência uma linguagem mais acessível, mais próxima dos estudantes?

Esse aspecto é abordado no estudo de Costa, professor de fotografia com dois anos e meio de docência na UFG, que assim se posiciona:

Meu tema pretende trazer alguns apontamentos sobre estratégias para motivar os alunos no processo de ensino-aprendizagem. Foi escolhido por eu entender a relação professor-aluno como essencial no bom andamento das disciplinas e, por conseguinte, no aprendizado dos alunos. (COSTA, 20011, p. 1)

O motivo que impactou o docente e o mobilizou para realizar esse estudo foi a constatação de que os estudantes não leem, o que inviabiliza a discussão, o diálogo e a troca de experiências em sala de aula, além de acentuar a dificuldade de produzirem seus próprios escritos. Questionados sobre a situação, "as respostas eram bastante categóricas e intrigantes: 'não lemos; não temos tempo para ler seus textos'"' (p. 3).

Ao analisar o comportamento, a atitude e o desempenho dos alunos, o docente concluiu que eles não têm um repertório específico da área. 
Resolveu, então, investigar as expectativas dos alunos em relação ao papel do professor, partindo do pressuposto de que a relação professor-aluno deve ser mantida na base do diálogo e envolver negociações que motivem à aprendizagem.

O próximo passo foi ouvir os alunos. "Creio ser pertinente escutar a outra parte envolvida no processo ensino-aprendizagem, em defesa de um diálogo mais constante e contínuo" (COSTA, 2011, p. 5). À pergunta "O que significa para você um bom professor?", responderam 66 alunos matriculados em três disciplinas ministradas pelo docente. Nas respostas foram identificados pontos recorrentes, tais como: transmitir conhecimentos de forma clara e simples; ser acessível, pontual e não faltar às aulas; ser dedicado e amar o que faz. E outros destacados a seguir:

Um bom professor instiga o aluno a pensar com autonomia, a descobrir novos caminhos, a alçar voos para além da sua área de conforto ( 21 anos).

É aquele que consegue manter uma relação próxima ao aluno, entendendo suas capacidades e dificuldades ( 23 anos).

[...] é aquele que estimula o aluno a querer saber, dá ao aluno informações, recursos, base; é aquele que interage com os alunos, compreende-os, propõe atividades práticas interessantes (19 anos). (COSTA, 2011, p. 5-6)

Com base nessas expectativas e nas reflexões sobre os alunos - a falta de interesse pela leitura, a desmotivação, a insuficiência de conhecimentos culturais -, o professor busca referenciais teóricos e se interroga sobre a possibilidade de "criar alternativas para que a disciplina flua" (p. 8). Assim, em seu estudo de caso, relata que uma das estratégias adotadas em suas disciplinas (com boa repercussão) é pedir aos alunos, no início do semestre, que apresentem para a turma uma cartografia sentimental; esta consiste em um repertório que faz parte do contexto cultural de cada um e que desperte e represente seu desejo. Segundo Rolnik (1989, p.16, apud, COSTA, 2011, p. 9), "tudo o que servir para cunhar matéria de expressão e criar sentido" faz parte do trabalho do cartógrafo. De acordo com essa compreensão, e por analogia, o professor apresenta sua cartografia primeiro, para dar o exemplo de como fazer. Depois, um painel com as referências pessoais e culturais dos alunos é apresentado em aula.

De acordo com o autor, dois pontos positivos são apreendidos nessa prática:

Primeiro, o professor pode conhecer um pouco mais sobre o cotidiano e os gostos pessoais de seus alunos. Ter uma visão geral da turma e aproximar-se 
dela. E, segundo, o professor tem subsídios para usar na hora de preparar suas aulas e exercícios, sabendo que está falando a mesma língua que seus alunos. (COSTA, 2011, p. 9)

Além disso, a possibilidade de identificação entre os alunos e desses com o professor, por meio dos temas apresentados, é bastante provável, o que favorece sobremaneira as interações e a mobilização de interesses para estudos futuros. "[...] acreditamos que através de uma boa relação professoraluno podemos criar maneiras de provocar essa motivação, que por vezes perde-se na rotina de afazeres no percurso dos semestres" (p. 11).

Embora as relações pedagógicas constituam um importante aspecto das práticas acadêmicas, como demonstraram os professores iniciantes, elas não esgotam todas as suas manifestações que incluem, entre outras, relações institucionais, pessoais, espaciais, administrativas. Por isso, o investimento na inserção dos novos professores no campo da docência vem se configurando como necessidade e preocupação de diferentes instâncias da gestão acadêmica e tornando-se objeto do campo das políticas. O que se justifica pela centralidade atribuída à educação no projeto de desenvolvimento do país e revela o reconhecimento de que elevar a qualidade da educação implica aprimorar o desempenho docente por meio da formação, e sua satisfação com a profissão por meio das condições de trabalho e da valorização profissional, aspectos indissociáveis da política de profissionalização.

PEDAGOGICAL FORMATION OF THE UNIVERSITY PROFESSOR: A REFLECTION ON THE UFG PROPOSAL

ABSTRACT: The reference for this article is the Higher Education Teacher Formation Program (Programa Formação para a Docência no Ensino Superior), set up in 2006 by the Universidade Federal de Goiás. Drawing on academic research on teaching in higher education and on the production of the teacher participants, this article presents the program's proposed action and discusses the formation needs and specific knowledge for teaching at this level. Its aim is to socialize the experiences lived out in the institution. In this research, two types of data were analyzed: the profile of the participants and the themes discussed by these beginner university professors in their case studies presented at the end of the program. The discussion pointed to a framework of varied nuances: political, structural, organizational, epistemological and didactic-pedagogical. Of the twenty-eight themes presented, the one most frequently addressed was that of teacher and student motivation. It was found that formation needs go beyond the scope of pedagogy, which would suggest a relationship between the university context, teaching conditions and practice in the classroom. This would indicate that greater personal and institutional investment in teachers' professional development is necessary. 
Keywords: Higher Education teaching. UFG Teacher Formation Program. Professional development.

\section{FORMACIÓN PEDAGÓGICA DEL PROFESOR UNIVERSITARIO: UNA REFLEXIÓN SOBRE} LA PROPUESTA DE LA UFG

RESUMEN: Este artículo tiene como referencia el Programa de Formación para la Docencia en Enseñanza Superior, instituído por la Universidad Federal de Goiás en 2006. Presenta las acciones propuestas y discute las necesidades formadoras y los saberes específicos para la docencia en ese nivel de enseñanza, basándose en la producción académica sobre el tema y en la producción de los profesores participantes. Tiene como objetivo la socialización de las experiencias vividas en la institución. En esta investigación se sistematizaron datos referentes al perfil de los participantes, temáticas desarrolladas en los estudios de casos presentados al final de los cursos realizados por los profesores ingresantes. La discusión apuntó a un cuadro de diferentes órdenes: políticos, estructurales, organizacionales, epistemológicas, didáctico-pedagógicas. Entre los veintiocho ejes temáticos abordados, la mayor incidencia recayó sobre la motivación de los profesores y de los estudiantes. Se confirmó que las necesidades formadoras superan el ámbito pedagógico, sugiriendo una relación entre el contexto universitario, la condición de trabajo docente y la práctica en el aula. Eso indica una demanda de mayor inversión personal e institucional en el desarrollo profesional de los docentes.

Palabras Claves: Docencia en enseñanza superior. Programa de formación docente de la UFG. Desarrollo profesional.

\section{REFERÊNCIAS}

ANASTASIOU, L. G. C.; ALVES, L. P. (Org.) Processos de ensinagem na universidade: pressupostos para estratégia de trabalho em aula. Joinville, SC: Univille, 2003.

BEHRENS, M. A. A formação pedagógica e os desafios do mundo moderno. In: MASETTO, M. (Org.). Docência na universidade. 7. ed. São Paulo: Papirus, 2005.

BENEDITO, A. V. La formación universitaria a debate. Barcelona: Universitat de Barcelona, 1995.

BIREAUD, A. Os métodos pedagógicos no ensino superior. Porto, Portugal: Porto Editora, 1995.

BRASIL. Lei de Diretrizes e Bases da Educação Nacional - Lei n. 9394 de 20/12/96.

BRASIL. Programa de Expansão, Excelência e Internacionalização das Universidades Federais. Brasília: Andifes, 2012.

BRASIL. Plano Nacional de Graduação: um projeto em construção. In: Resgatando espaços e construindo ideias. 2. ed. 1997 a 2003. Disponível em: http://www.forgrad. com.br/publicacoes.php. Acesso em: 25 mar. 2012. 
BZUNECK, J. A. A motivação dos alunos: aspectos Introdutórios. In: BORUCHOVITCH, E. \& BZUNECK, J. A. (Org.). A motivação do aluno: contribuições da psicologia contemporânea. Petrópolis: Vozes, 2001.

COSTA, E. R; SILVA, H. M S.; RODRIGUES, J. F; DIAS, M.; ASSIS, R. M.; SANTEIRO, T. V. Motivação no ensino superior: estudo de caso com acadêmicos de zootecnia. Curso Formação para a Docência no Ensino Superior da UFG, Campus Jataí, 2010. (digitado)

COSTA, O. Estratégias para motivar o ensino-aprendizagem na FAV-UFG: a relação professor-aluno como base. Curso Formação para a Docência no Ensino Superior da UFG, Campus Goiânia, 2011. (digitado)

CUNHA, M. I.O bom professor e sua prática. Campinas: Papirus, 1992.

CUNHA, M. I.; FERNANDES, L. Formação continuada de professores universitários: uma experiência na perspectiva da produção do conhecimento. In: Anais, VII ENDIPE, Goiânia, 1994.

CUNHA, M. I.; LEITE, D. Decisões pedagógicas e estruturas de poder na universidade. Campinas: Papirus, 1996.

CUNHA, M. I. A aula universitária: inovação e pesquisa. In: LEITE, D.; MOROSINI, M. Universidade futurante. Campinas: Papirus, 1997.

CUNHA, M. I. O professor universitário na transição de paradigmas. Araraquara: JM, 1998.

CUNHA, M. I. A universidade: desafios políticos e epistemológicos. In: CUNHA, M. I. (Org). Energias emancipatórias em tempos neoliberais. Araraquara, SP: Junqueira \& Marin, 2006. p. 13-29.

CUNHA, M. I. (Org). Trajetórias e lugares de formação da docência universitária: da perspectiva individual ao espaço institucional. Araraquara, SP: Junqueira \&Marin; Brasília, DF: CAPES/CNPq, 2010.

Demo, P. Educar pela pesquisa. São Paulo: Autores Associados, 1996.

ESTEVE, J. M. O mal-estar docente: a sala de aula e a saúde dos professores. Bauru: EDUSC, 1999.

GUSDORF, G. Present, passe avenir de La recherche interdisciplinaire. Rev. Int. de Sciences Sociales, n. 29, 1977, p. 627- 48.

HUBERMAN, M. O Ciclo de vida profissional dos professores. In: NÓVOA, A. (org.). Vidas de professores. 2. ed. Portugal: Porto Editora, 1992.

MARCELO GARCIA, C. Formação de Professores: para uma mudança educativa. Portugal: Porto Editora, 1999.

MARQUES, M. O. A formação do profissional da Educação. ljuí: UNIJUI, 1992.

MASETTO, M. O professor no Ensino Superior Brasileiro. 1982. Tese (Doutorado em Educação). PUC, São Paulo.

MASETTO, M. O professor universitário em sala de aula: prática e princípios teóricos. São Paulo: M. G. Associados, 1990. 
MASETTO, M. Aula na universidade. Anais... VIII ENDIPE, Florianópolis, 1996.

MASETTO, M. (Org.). Docência na universidade. Campinas, São Paulo: Papirus, 1998.

MOROSINI, M. Seara de desencontros: a produção do ensino na universidade. 1990. Tese (Doutorado em Educação). UFRGS, Porto Alegre.

MOROSINI, M.; FRANCO, M. Redes acadêmicas: a melhoria do ensino e a formação de professores universitários. In: CONGRESSO INTERNACIONAL SOBRE FORMAÇÃO DE PROFESSORES NOS PAÍSES DE LÍNGUA E EXPRESSÃO PORTUGUESAS. Anais... Porto Alegre: PUCRS, 1997.

MOROSINI, M. A produção da pesquisa frente à produção do ensino na universidade. Universidade \& Pesquisa: Institucionalização, produção e políticas de pesquisa na universidade. Cadernos de Sociologia, UFRS/ Programa de Pós-graduação em Sociologia Porto Alegre, v. 8, p.101-125, dez.1998.

MOROSINI, M. (Org.). Professor do ensino superior: identidade, docência e formação. Brasília: INEP, 2000.

NÓVOA, A. (Org.). Vidas de professores. 2. ed. Portugal: Porto Editora, 1992.

OLIVEIRA JUNIOR, A. C.; COSTA, L. C.; DUARTE, M. A.; SILVEIRA, R. W. M.; BARROS, R. A. C. $O$ isolamento dos docentes e a falta de interdisciplinaridade no planejamento e nas práticas dos cursos de graduação. Curso Formação para Docência no Ensino Superior da UFG, Campus Catalão, 2007. (digitado)

PIMENTA, S. G.; ALMEIDA, M. I. (Org). Pedagogia universitária. São Paulo: Editora da USP, 2009.

PIMENTA, S. G.; ALMEIDA, M. I. (Org.). Caminhos para a formação de professores. São Paulo: Cortez, 2011.

PIMENTA, S. G.; ANASTASIOU, L. G. C. Docência no ensino superior. São Paulo: Cortez, 2002.

ROLNIK, S. Cartografia sentimental: transformações contemporâneas do desejo. São Paulo: Estação da Liberdade, 1989.

ROSA, D. E. G. Investigação-ação colaborativa sobre práticas docentes na formação continuada de formadores. 2003. Tese (Doutorado em Educação). UNIMEP, Piracicaba, SP.

SILVA, A. R. C. A.; COSTA, A. G.; ANDRADE, C. R.; OLIVEIRA, D. S.; CORREAA, R. S.; STEIN, V. C. Influência do tempo de docência na motivação dos alunos da UFG - Campus Jataí. Curso formação para a docência no ensino superior da UFG, Campus Jataí, 2011. (digitado) SOUZA, A. S.; ANTUNES, D. E. ; VALENÇA, K. B. C.; OLIVEIRA, N. D. G. L.; MELO, R. M. Qualidade de vida e trabalho docente: uma via de mão dupla? Curso Formação para a Docência no Ensino Superior da UFG, Campus Goiânia, 2011 (digitado).

TAPIA, J. A.; FITA, E. C. A motivação em sala de aula: o que é, como se faz. 7. ed. São Paulo: Loyola , 2006.

TARDIF, M. Saberes docentes e formação profissional. Petrópolis, Vozes, 2002. 
DALVA ETERNA GONÇALVES ROSA é professora adjunta da Universidade Federal de Goiás; mestre e doutora em Educação; atua no campo da Didática e Formação de Professores no curso de Pedagogia e no Programa de Mestrado em Educação em Ciências e Matemática da UFG; é coordenadora do Programa de Formação para a Docência no Ensino Superior, nessa mesma instituição.

E-mail: dalvagr@uol.com.br

SANDRAMARA MATIAS CHAVES é professora adjunta da Universidade Federal de Goiás; mestre e doutora em Educação; atua no campo da Didática, Avaliação da Aprendizasem e Formação de Professores no curso de Pedagogia e no Programa de Mestrado em Educação em Ciências e Matemática da UFG. Atualmente ocupa o cargo de Pró-Reitora de Graduação no IES.

E-mail: sandramara@prograd.ufg.br 